\title{
ATIVIDADE ALELOPÁTICA DE ESPÉCIES INVASORAS SOBRE A GERMINAÇÃO E O DESENVOLVIMENTO INICIAL DE ARBÓREA NATIVA
}

\author{
Katia Cristina Dalpiva Hartmann*, Andréa Maria Teixeira Fortes², Flávia Danieli Rech Cassol², \\ Raquel Valmorbida ${ }^{2}$, Lorena Camargo de Mendonça ${ }^{3}$ \\ 1* Universidade Estadual do Oeste do Paraná, Centro de Ciências Biológicas e da Saúde, Cascavel, Paraná, Brasil - \\ katiachartmann@gmail.com \\ ${ }^{2}$ Universidade Estadual do Oeste do Paraná, Programa de Pós-Graduação em Conservação e Manejo de Recursos Naturais. Cascavel, Paraná, \\ Brasil - amtfortes@hotmail.com; raquelvalmorbida@yahoo.com.br \\ ${ }^{3}$ Universidade Estadual do Oeste do Paraná, Programa de Pós-Graduação em Engenharia Agrícola. Cascavel, Paraná, Brasil - \\ fdr@hotmail.com; lorena.c.mendonca@hotmail.com \\ Recebido para publicação: 17/01/2017 - Aceito para publicação: 05/06/2017
}

\begin{abstract}
Resumo
Plantas invasoras surgem durante a sucessão ecológica e se desenvolvem juntamente com arbóreas nativas. A convivência entre essas espécies pode ser influenciada por vários fatores, como a alelopatia, definida como o conjunto de alterações diretas ou indiretas, que uma planta exerce sobre outra. Assim o objetivo do trabalho foi identificar a existência da ação alelopática na germinação das sementes e a possível interferência no crescimento inicial de plântulas de $P$. rigida quando submetidas aos extratos aquosos de $B$. brizantha e $M$. maximus. Para tanto, foi utilizado um DIC em esquema fatorial $2 \mathrm{X} 4$ (espécies $\mathrm{x}$ tratamentos). Foi preparado o extrato aquoso de folhas frescas das espécies invasoras, de forma independente, os quais foram diluídos nas proporções 2,5; 5; e $10 \%$ e como testemunha utilizou-se água destilada $(0 \%)$. As sementes e plântulas de $P$. rigida foram submetidas aos diferentes extratos e avaliadas quanto aos parâmetros: germinação, índice de velocidade de germinação, crescimento de raiz e parte aérea e peso da massa seca. Após análise dos dados, foi possível verificar que ambos os extratos não apresentaram interferência alelopática na germinação e no índice de velocidade de germinação das sementes de $P$. rigida, assim como no crescimento das raízes de suas plântulas. No entanto, quando as plântulas foram submetidas ao extrato de M. maximus nas duas maiores concentrações foi observado maior crescimento da parte aérea. Sendo assim, não há interferência alelopática negativa dos extratos de $B$. brizantha e M. Maximus na germinação das sementes ou no crescimento inicial de $P$. rigida.

Palavras-chave: Alelopatia; gramíneas; invasão biológica.
\end{abstract}

\begin{abstract}
Alelopathic activity of invasive species on the germination and initial development of native tree. Invasive plants arise during ecological succession and develop along with native trees. The coexistence between these species can be influenced by several factors, such as allelopathy, defined as the set of direct or indirect changes that one plant exerts on another. Thus, the objective of this work was to identify the existence of allelopathic action on seed germination and the possible interference in the initial growth of $P$. rigida seedlings when submitted to aqueous extracts of $B$. brizantha and M. maximus. For this, a DIC was used in a $2 \mathrm{X} 4$ factorial scheme (species $\mathrm{x}$ treatments). The aqueous extract of fresh leaves of the invasive species was prepared independently, which were diluted in the proportions 2.5; 5; And $10 \%$ and distilled water (0\%) was used as control. Seeds and seedlings of $P$. rigida were submitted to different extracts and evaluated for germination, germination speed index, root and shoot growth and dry mass weight. After analyzing the data, it was possible to verify that both extracts did not present allelopathic interference in the germination and germination speed index of $P$. rigida seeds, as well as in the growth of the roots of their seedlings. However, when the seedlings were submitted to the extract of M. maximus in the two higher concentrations, greater shoot growth was observed. Thus, there is no negative allelopathic interference of $B$. brizantha and $M$. Maximus extracts on seed germination or on initial growth of $P$. rigida.

Keywords: Allelopathy; grass; biological invasive.
\end{abstract}

\section{INTRODUÇÃO}

A invasão biológica é caracterizada quando uma espécie animal ou vegetal é transportada para outras áreas, ocupando um espaço fora de sua área geográfica, com adaptação da espécie e alteração do ecossistema.

FLORESTA, Curitiba, PR, v. 47, n. 3, p. 229 - 235, jul. / set. 2017

Hartmann, K. C. D. et al.

ISSN eletrônico 1982-4688

DOI: $10.5380 /$ rf.v47i1.50222 
Tal fenômeno apresenta um inexorável impacto sobre as biotas nativas de todo o planeta, sendo ela um significativo agente de desequilíbrio ambiental. (NOVACEK; CLELAND, 2001).

A biota mundial tem sido modificada por invasões biológicas, provocando mudanças no papel de espécies nativas em comunidades, alterando processos evolutivos e a abundância de espécies, por vezes levando à extinção. Como consequência, a introdução de espécies invasoras é atualmente considerada uma das maiores ameaças à diversidade biológica em escala global, inclusive em unidades de conservação (SPEAR et al., 2013).

No Brasil, várias espécies de gramíneas africanas como Brachiaria brizantha (Hochst. ex A. Rich.) Stapf e Megathyrsus maximus (JACQ.) B.K. Simon \& S.W.L Jacobs, foram introduzidas acidentalmente ou para fins forrageiros, tornando-se invasoras de ecossistemas naturais, principalmente dos ambientes abertos, como campos e cerrados (FREITAS; PIVELLO, 2005). Sendo capaz de causar efeitos negativos no estabelecimento e desenvolvimento das espécies nativas, pois competem pelos recursos nutricionais do solo, que pode acarretar mudanças na morfofisiologia vegetal e na quantidade e qualidade dos nutrientes absorvidos (MATOS; PIVELLO, 2009; VILÀ et al., 2011).

Uma árvore nativa de grande ocorrência no sul do Brasil e encontrada nos locais em regeneração natural, convivendo e competindo com espécies invasoras é a Parapiptadenia rigida (BRENTH) BRENAN, pertencente à família Fabaceae é popularmente conhecida como angico-vermelho. Essa espécie é considerada bastante agressiva e por ser uma pioneira de crescimento espontâneo é indicada para a recuperação de áreas degradadas (LORENZI, 2014). Nos locais em renovação natural, o banco de sementes que se formou no solo contribui para o processo de restauração da área, mantendo este um papel fundamental no equilíbrio dinâmico da floresta (CALEGARI et al., 2013).

Após a maturação dos frutos das arbóreas nativas, ocorre a chuva de sementes. Que ao serem depositadas no solo estão suscetíveis à ação de substâncias ali presentes, que foram liberadas por outras plantas do ecossistema. A permanência e sobrevivência das sementes no banco e o desenvolvimento das plântulas nas reservas do solo dependem de fatores bióticos e abióticos, como da presença de fatores inibitórios, incluindo os compostos alelopáticos (MALLIK, 2008).

As plantas de uma formação vegetal irão dividir o mesmo espaço e a interação entre elas está presente sob a forma de competição, como por exemplo, nas interferências alelopáticas. A alelopatia é definida como qualquer alteração direta ou indireta que uma planta exerce sobre a outra através de metabólitos secundários denominados aleloquímicos (SILVA et al., 2011).

Essas substâncias são produzidas através do metabolismo secundário e liberadas por diferentes vias como pela lixiviação dos tecidos, pela dissolução em água, pela volatilização de compostos aromáticos, influenciando direta ou indiretamente nas interações entre plantas. Esses aleloquímicos estão presentes em diferentes órgãos das plantas e as funções biológicas mais prejudicadas nos vegetais são, entre outras, o crescimento e a atividade fotossintética. O meio mais comum para determinar o potencial alelopático de uma planta é o estudo do efeito do extrato vegetal sobre sementes ou plântulas de espécies alvo. (ZENG et al., 2010).

A alelopatia vem sendo adotada como um importante mecanismo ecológico, influenciando a vegetação existente em um ecossistema (OLIVEIRA, et al., 2011). Sendo assim, esse trabalho teve por objetivo avaliar a existência do efeito alelopático dos extratos aquosos de B. brizantha e $M$. maximus quando aplicados na germinação das sementes e no crescimento inicial das plântulas de $P$. rigida.

\section{MATERIAL E MÉTODOS}

O trabalho foi realizado na Universidade Estadual do Oeste do Paraná - campus Cascavel. As sementes da espécie nativa $P$. rigida foram doadas pelo Instituto Ambiental do Paraná (IAP), da cidade de Cascavel. Os extratos aquosos utilizados nos testes de germinação das sementes e desenvolvimento das plântulas de $P$. rigida foram obtidos de folhas frescas das plantas invasoras $B$. brizantha e $M$. maximus, coletadas nas estações primavera/verão (2013) em seu estádio vegetativo, em locais em regeneração como lavouras abandonadas e

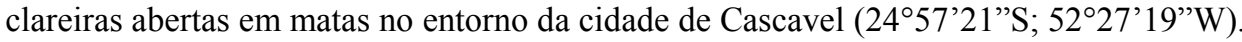

Para o preparo dos extratos aquosos, as folhas das espécies invasoras foram coletadas, pesadas, picadas e trituradas em liquidificador, seguindo a proporção $200 \mathrm{~g}$ de material vegetal fresco para $1 \mathrm{~L}$ de água destilada. $\mathrm{O}$ extrato foi filtrado em malha fina e a partir deste, foram realizadas as diluições: 2,$5 ; 5$ e $10 \%$ tanto para $B$. brizantha como para M. maximus. Após esse procedimento, foi aferido o $\mathrm{pH}$ da água utilizada e das diluições realizadas.

\section{Bioensaios de germinação das sementes de $P$. rigida}

As sementes de $P$. rigida foram beneficiadas visualmente, sendo descartadas as que continham alguma avaria, homogeneizadas e desinfetadas com hipoclorito de sódio (20\%). Os rolos de papel germitest, utilizados como substrato, foram autoclavados $\left(120^{\circ} \mathrm{C}\right)$ e posteriormente umedecidos: com água destilada, compondo as 
testemunhas e para os tratamentos, com os extratos das espécies invasoras, nas diluições realizadas $(2,5,5$ e $10 \%$ ), foi mantida a proporção de 2,5 vezes o peso do papel (BRASIL, 2009). Cada tratamento foi composto por quatro repetições, contendo 25 sementes da espécie nativa, distribuídas sobre o substrato, para cada extrato.

Após semeadura, os rolos de papel foram acondicionados em sacos plásticos e levados para câmaras de germinação (BOD) com fotoperíodo de 12 horas e temperatura constante de $25^{\circ} \mathrm{C}$ (MONDO, 2008). A contagem das sementes germinadas foi realizada em intervalos de 24 horas durante o período de sete dias. E o critério utilizado para a avaliação foi a medida do comprimento de $2 \mathrm{~mm}$ da raiz primária.

Bioensaio de desenvolvimento das plântulas de $P$. rigida

Para a produção de plântulas foram pré-germinadas 320 sementes de $P$. rigida, suficientes para cada um dos tratamentos (testemunha $0 \%$, extratos de B. brizantha e M. maximus a 2,5, 5 e $10 \%$ ), em papel germitest autoclavado e umedecido somente com água destilada, na proporção de 2,5 vezes o peso do papel (BRASIL, 2009) foram dispostas 10 sementes por repetição, e estas foram armazenadas em câmara de germinação $\left(12 \mathrm{~h} / 25^{\circ} \mathrm{C}\right)$. Após as sementes germinarem e suas raízes primárias atingirem tamanho aproximado a $2 \mathrm{~mm}$, as mesmas foram transferidas para novos rolos de papel germitest, reproduzindo as mesmas condições do teste de germinação.

Os rolos de papel contendo as sementes germinadas foram acondicionados em sacos plásticos, colocados na posição vertical dentro de garrafas pet e levados para câmaras de germinação com fotoperíodo de 12 horas e temperatura constante de $25^{\circ} \mathrm{C}$, pelo período de sete dias. Foram medidas a raiz primária e a parte aérea de 5 plântulas normais de cada repetição com o auxílio de uma régua graduada em centímetros, sendo os resultados expressos em $\mathrm{cm} /$ plântula. A média que corresponde a parte aérea foi feita do colo da plântula até a gema apical. Para a raiz mediu-se do colo da plântula até a extremidade final da raiz primária.

Para a realização dos bioensaios foi utilizado o delineamento experimental inteiramente casualizado (DIC) em esquema fatorial 2X4 (duas espécies x quatro tratamentos), com quatro repetições. Os parâmetros avaliados na germinação foram: porcentagem de germinação (PG \%) e índice de velocidade de germinação (IVG). Para o desenvolvimento das plântulas os parâmetros avaliados foram comprimento da raiz $(\mathrm{cm})$, comprimento da parte aérea $(\mathrm{PA})(\mathrm{cm})$ e peso da massa seca $(\mathrm{g})$. Os dados considerados não normais foram transformados por boxcox, e os valores expressos em porcentagem foram transformados por arco seno x/100 (BRASIL, 2009). Os resultados foram submetidos à análise de variância (ANOVA) e as médias comparadas pelo teste de Tukey, a 5\% de probabilidade, pelo programa R, versão 3. 2. 5 (R DEVELOPMENT CORE TEAM, 2016).

\section{RESULTADOS}

Os valores referentes ao $\mathrm{pH}$, apresentados na figura 1 , indicam que os extratos aquosos de $B$. brizantha e $M$. maximus, para todas as suas diluições, encontravam-se em uma faixa próxima da neutralidade. Conforme os dados é possível verificar que os valores desse parâmetro para o extrato de $B$. brizantha, apresentaram variação entre 6,92-5,95. Enquanto no extrato de $M$. maximus, o pH manteve-se na faixa de 7,05-6,32. Em ambos os extratos nota-se um decréscimo no valor do $\mathrm{pH}$ com o aumento das concentrações dos extratos.

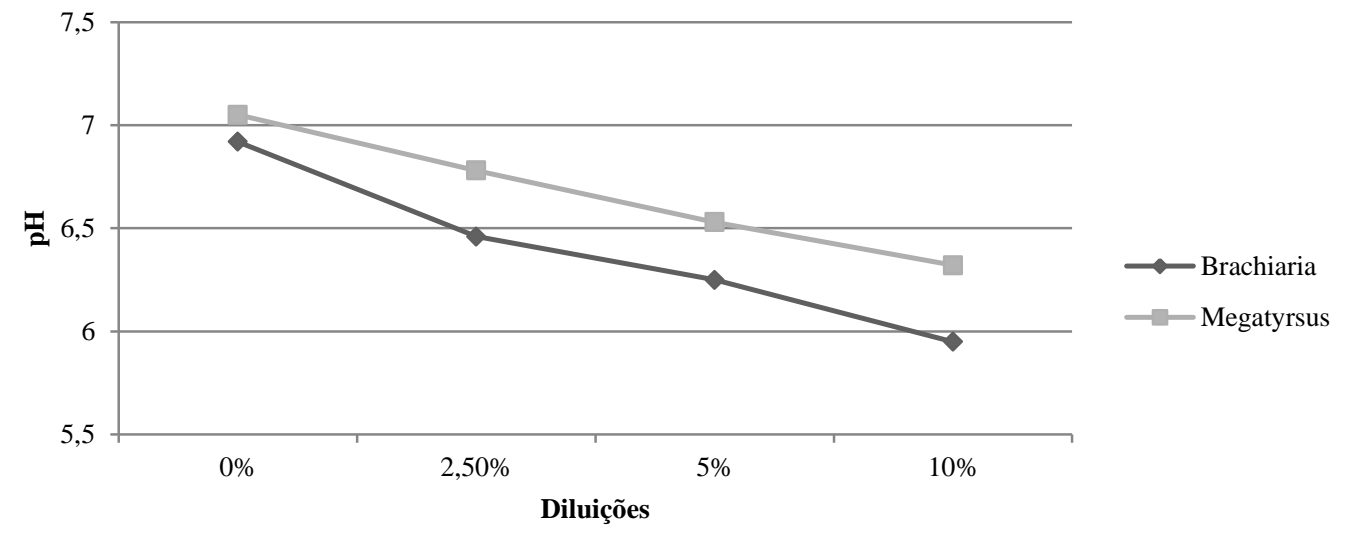

Figura 1. Valores médios do pH dos extratos de Brachiaria brizantha e Megatyrsus maximus em suas diferentes diluições (Cascavel (PR), 2017).

Figure 1. Mean $\mathrm{pH}$ values of the extracts of Brachiaria brizantha and Megatyrsus maximus in their different dilutions (Cascavel (PR), 2017).

FLORESTA, Curitiba, PR, v. 47, n. 3, p. 229 - 235, jul. / set. 2017

Hartmann, K. C. D. et al.

ISSN eletrônico 1982-4688

DOI: $10.5380 /$ rf.v47i1.50222 
Na tabela 1, estão dispostos os valores referentes a Porcentagem de Germinação (PG) e do índice de velocidade de germinação (IVG) das sementes de $P$. rigida após serem submetidas aos extratos aquosos de $B$. brizantha e M. maximus. Tanto na PG, quanto no IVG não foi observado interação alelopática na germinação. A porcentagem de germinação das sementes de $P$. rigida manteve-se acima de $95 \%$, mostrando alta viabilidade mesmo na presença dos extratos.

Tabela 1. Valores médios da porcentagem de germinação e do índice de velocidade de germinação (IVG) das sementes de Parapiptadenia rigida, submetidas as diferentes diluições dos extratos de Brachiaria brizantha e Megatyrsus maximus. (Cascavel (PR), 2017).

Table 1. Mean values of germination percentage and germination velocity index (GVI) of Parapiptadenia rigida seeds, submitted to different dilutions of Brachiaria brizantha and Megatyrsus maximus extracts. (Cascavel (PR), 2017).

\begin{tabular}{ccccc}
\hline & \multicolumn{2}{c}{ Germinação (\%) } & \multicolumn{2}{c}{ IVG } \\
\cline { 2 - 5 } Diluições \% & Brachiaria brizantha & Megatyrsus maximus & Brachiaria brizantha & Megatyrsus maximus \\
\hline 0 & 98 & 99 & 11,42 & 13,02 \\
2,5 & 96 & 97 & 12,72 & 13,06 \\
5 & 97 & 98 & 12,77 & 12,98 \\
10 & 99 & 99 & 13,56 & 13,11 \\
\hline CV & \multicolumn{2}{c}{}
\end{tabular}

Em que: $\mathrm{CV}=$ coeficiente de Variação. Dados não diferem ao nível de significância de $5 \%$ pelo teste de Tukey.

Na tabela 2 encontram-se os resultados referentes ao crescimento da raiz e da parte aérea das plântulas de $P$. rigida submetidas aos extratos aquosos de $B$. brizantha e $M$. maximus em suas diferentes diluições. Após a análise, os resultados mostraram à inexistência do efeito alelopático no crescimento das raízes.

Quando observados os dados do crescimento da parte aérea das plântulas de $P$. rigida, verifica-se que as médias referentes aos tratamentos realizados com o extrato de B. brizantha, são estatisticamente iguais. Já nos valores médios dos tratamentos com o extrato de M. maximus e entre os extratos das invasoras, foi constatada interação, logo, foram realizados os desdobramentos da ANOVA.

Analisado os valores referentes ao crescimento das plântulas submetidas aos extratos de M. maximus (Tabela 2), observa-se que as diluições 0, 2,5 e 5\% são estatisticamente iguais entre si. Enquanto a diluição $10 \%$ difere significativamente das demais, apresentando maior valor de crescimento de parte aérea das plântulas nativas. Comparando os dados entre os extratos das espécies invasoras, observa-se que nas diluições de 0 e 2,5\%, os valores médios de parte aérea são estatisticamente iguais. Já para as diluições 5 e $10 \%$, verificou-se que as plântulas submetidas ao extrato de $M$. maximus apresentaram maior crescimento dessa variável quando comparadas as testadas com o extrato de $B$. brizantha.

Tabela 2. Valores médios do crescimento da raiz e da parte aérea das plântulas de Parapiptadenia rigida submetidas aos extratos aquosos de Brachiaria brizantha e Megatyrsus maximus, no sétimo dia após a germinação. (Cascavel (PR), 2017).

Table 2. Mean values of root and shoot growth of Parapiptadenia rigida seedlings submitted to the aqueous extracts of Brachiaria brizantha and Megatyrsus maximus, on the seventh day after germination. (Cascavel (PR), 2017).

\begin{tabular}{ccccc}
\hline & \multicolumn{2}{c}{ Raiz $\mathbf{( c m )}$} & \multicolumn{2}{c}{ Parte aérea (cm) } \\
Diluições \% & Brachiaria brizantha & Megatyrsus maximus & Brachiaria brizantha & Megatyrsus maximus \\
\hline 0 & 6,41 & 5,0 & $4,17 \mathrm{aA}$ & $3,95 \mathrm{bA}$ \\
2,5 & 5,81 & 4,48 & $3,60 \mathrm{aA}$ & $3,8 \mathrm{bA}$ \\
5 & 4,66 & 5,19 & $3,58 \mathrm{aB}$ & $4,96 \mathrm{bA}$ \\
10 & 4,83 & 4,36 & $4,37 \mathrm{aB}$ & $5,43 \mathrm{aA}$ \\
\hline $\mathrm{CV}$ & $21,1 \%$ & & $14,7 \%$ \\
\hline
\end{tabular}

Em que: $\mathrm{CV}=$ coeficiente de Variação. Médias seguidas pela mesma letra minúscula na coluna e maiúscula na linha não diferem estatisticamente entre si pelo Teste de Tukey a $5 \%$ de probabilidade.

Na tabela 3 estão dispostas as médias referentes ao peso da massa seca da raiz e da parte aérea das plântulas de $P$. rigida submetidas aos extratos de $B$. brizantha e $M$. maximus, observa-se que, não houve interação significativa. A quantidade de massa seca de raiz foi muito similar para ambos os extratos com variação de $35 \mathrm{~g}$ entre a maior e a menor média para cada extrato $(0 \%$ e $10 \%)$. 
Tabela 3. Peso médio da massa seca da raiz e da parte aérea das plântulas de Parapiptadenia rigida desenvolvidas sob os extratos de Brachiaria brizantha e Megatyrsus maximus, no sétimo dias após a germinação. (Cascavel (PR), 2017).

Table 3. Mean weight of root and shoot dry weight of Parapiptadenia rigida seedlings developed under the extracts of Brachiaria brizantha and Megatyrsus maximus, at the seventh day after germination. (Cascavel (PR), 2017).

\begin{tabular}{ccccc}
\hline & \multicolumn{2}{c}{ Raiz $(\mathbf{g})$} & \multicolumn{2}{c}{ Parte aérea $(\mathbf{g})$} \\
\cline { 2 - 5 } Diluições $\%$ & Brachiaria brizantha & Megatyrsus maximus & Brachiaria brizantha & Megatyrsus maximus \\
\hline 0 & 14,40 & 14,40 & 12,09 & 12,09 \\
2,5 & 14,78 & 14,41 & 11,61 & 11,83 \\
5 & 14,83 & 15,35 & 11,60 & 12,30 \\
10 & 15,84 & 13,26 & 12,07 & 11,58 \\
\hline CV & \multicolumn{3}{c}{}
\end{tabular}

Em que: $\mathrm{CV}=$ Coeficiente de variação. Dados não diferem significativamente a 5\% de probabilidade pelo teste de Tukey.

\section{DISCUSSÃO}

Os valores do $\mathrm{pH}$ obtidos neste estudo estão próximos da neutralidade e não interferiram no processo germinativo, visto que tanto a germinação como o crescimento das plantas são afetados negativamente apenas em condições em que o meio esteja extremamente ácido ou extremamente alcalino (SOUZA FILHO; DUTRA, 2000). A alta taxa de germinação das sementes de $P$. rigida pode estar relacionada ao fato de que a germinação é menos susceptível aos compostos alelopáticos. Segundo Ferreira e Aquila (2000), a plântula é um parâmetro de observação mais sensível aos aleloquímicos do que a germinação, pois esse fenômeno é discreto, sendo determinado pela semente germinada ou não.

As espécies vegetais são capazes de produzir e liberar compostos como alcaloides, terpenos e compostos fenólicos, substâncias essas com capacidade de interferir alelopaticamente na germinação. Porém, no caso deste estudo não foi observada tal atividade. Essa não intervenção alelopática na germinação pode ser resultante das baixas concentrações dos aleloquímicos nos extratos aplicados nas sementes ou pela resistência da espécie alvo a esses compostos presentes nos extratos (SILVA; AQÜILA, 2006). Sabe-se que as propriedades biológicas das substâncias alelopáticas podem ser alteradas, assim como seus efeitos. Os fatores determinantes para essa mudança são: fonte do extrato, forma de obtenção, concentração e as condições climáticas a qual estão expostas. Esses parâmetros podem influir nas respostas da bioatividade, devido ao risco da instabilidade dos princípios ativos (REICHEL et al., 2013).

Todas as plantas tem a capacidade de produzir diferentes tipos de metabolitos secundários, e estas substâncias alelopáticas podem atuar sobre os membros do ambiente em que a planta está inserida (INOUE $e t$ al., 2010). A quantidade de substâncias produzidas e sua composição variam de acordo com cada espécie de planta e das condições do meio em que ela esta inserida (SILVA; SILVA, 2007). A alelopatia é a "ciência que estuda qualquer processo envolvendo metabólitos secundários produzidos pelas plantas, algas, bactérias e fungos que influenciam o crescimento e o desenvolvimento de sistemas agrícolas e biológicos, incluindo efeitos positivos e negativos" (MACIAS et al., 2000).

Sendo assim, o crescimento distinto da parte aérea das plântulas nativas submetidas as maiores concentrações (5 e 10\%) do extrato de M. maximus ocorrido neste experimento enquadra-se como sendo um estimulo positivo. Não se pode afirmar com certeza qual o processo fisiológico desencadeado que influenciou esse crescimento, mas ele pode ter resultado da ação provocado pelos aleloquímicos, quando presentes em baixa quantidade, fenômeno conhecido como efeito de hormese.

$\mathrm{O}$ efeito de hormese ou efeito hormético, ocorre quando uma substância tóxica, em doses muito menores da que apresenta toxicidade, estimula o desenvolvimento da planta. Pesquisas como a de Calabrese e Blain (2009), demonstraram que certos compostos podem atuar como promotores ou fitohormônios de crescimento. O conceito de alelopatia envolve tanto os efeitos deletérios como os estimulatórios. Onde, estes últimos manifestam-se em situação de baixa concentração (SOUZA FILHO et al., 2005).

Por fim, relacionando a germinação das sementes e o crescimento diferenciado das partes aéreas das plântulas de $P$. rigida submetidas aos extratos das espécies invasoras, podem-se assumir duas vias. A primeira que a espécie nativa possui barreiras fisiológicas aos aleloquímicos presentes nos extratos das espécies invasoras em questão. E a segunda, que ao observar o efeito de hormese pode-se admitir que a porcentagem das doses dos extratos aplicados fosse relativamente baixa para se promover a ação alelopática.

FLORESTA, Curitiba, PR, v. 47, n. 3, p. 229 - 235, jul. / set. 2017 


\section{CONCLUSÃO}

- Os extratos aquosos de Brachiaria brizantha e Megatyrsus maximus não apresentam efeito alelopático negativo na germinação das sementes ou no crescimento inicial das plântulas de Parapiptadenia rigida.

\section{REFÊRENCIAS}

BRASIL, Ministério da Agricultura Pecuária e Abastecimento. Regras para Analise de Sementes. Brasília: MAPA/ACS, 1 ed. 2009. 399p.

CALABRESE, E. J.; BLAIN, R. B. Hormesis and plant biology. Environmental Pollution, Amsterdam, v. 157, p. 42-48, 2009.

CALEGARI, L.; MARTINS, S. V.; CAMPOS, L. C.; SILVA, E.; GLERIANI, J. M. Avaliação do banco de sementes do solo para fins de restauração florestal em Carandaí, MG. Revista Árvore, Viçosa, v. 37, n. 5, p. 871-880, 2013.

FERREIRA, A. G.; AQÜILA, M. E. A. Alelopatia: uma área emergente da ecofisiologia. Revista Brasileira de Fisiologia Vegetal, Campinas, v. 12, p. 175-204, 2000.

FREITAS, G. K.; PIVELLO, V. R. A ameaça das gramíneas exóticas à biodiversidade. In: V.R. Pivello; E.M. Varanda. O Cerrado Pé-de-Gigante (Parque Estadual de Vassununga, São Paulo) Ecologia e Conservação. 1 ed. São Paulo: Secretaria de Estado do Meio Ambiente, 2005, p. 283-296.

INOUE M. H.; SANTANA, D. C.; SOUZA FILHO, A. P. S.; POSSAMAI, A. C. S.; SILVA, L. E.; PEREIRA, M. J. B.; PEREIRA, K. M. Potencial alelopático de Annona crassiflora: efeitos sobre plantas daninhas. Planta Daninha, Viçosa, v. 28, n. 3, p. 489-498, 2010.

LORENZI, H. Árvores Brasileiras: manual de identificação e cultivo de plantas arbóreas nativas do Brasil. Nova Odessa: Instituto Plantarum, 6 ed. 2014, 384p.

MACIAS, F. A.; GALINDO, J. C. G.; MOLINILLO, J. M. G. Plant biocommunicators: application of allelopathic studies. In: J. C. Luijendijk. 2000 years of natural products research past, present and future. Phytoconsult: Teus, 2000, p. 26-30.

MALLIK, A. U. Allelopathy in forested ecosystems. In: ZENG, R. S.; MALLIK, A. U.; LUO, S. M. (Eds). Allelopathy in sustainable agriculture and forestry. New York: Springer, 2008, p. 363-386.

MATOS, D. M. S.; PIVELLO, V. R. O impacto das plantas invasoras nos recursos naturais de ambientes terrestres - alguns casos brasileiros. Ciência e Cultura, São Paulo, v. 61, n. 1, p. 27-30, 2009.

MONDO, V. H. V.; BRANCALION, P. H. S.; CICERO, S. M.; NOVEMBRE, A. D. L. C.; DOURADO NETO, D. Teste de Germinação de sementes de Parapiptadenia rigida (BRENTH.) BRENAN (FABACEAE). Revista Brasileira de Sementes, São Paulo, v. 30, n. 2, p. 77-183, 2008.

NOVACEK, M. J.; CLELAND, E. E. The current biodiversity extinction event: Scenarios for mitigation and recovery. Proceedings of the National Academy of Sciences, Washington v. 98, n. 10, p. 5466-5470, 2001.

OlIVEIRA, L. G. A.; BELINELO, V. J.; ALMEIDA, M. S.; AGUILAR, E. B.; VIEIRA FILHO, S. A. Alelopatia de Emilia sonchifolia (L.) DC. (Asteraceae) na germinação e crescimento inicial de sorgo, pepino e picão preto. Enciclopédia Biosfera, Centro Científico Conhecer, Goiânia, v. 7, n. 12, p. 01-10, 2011.

R DEVELOPMENT CORE TEAM. R: A language and environment for statistical computing. R Foundation for Statistical Computing, Vienna, Austria. 2016. ISBN 3-900051-07-0, URL http://www.R-project.org/.

REICHEL, T.; BARAZETTI, J. F.; STEFANELLO, S.; PAULERT, R.; ZONETTI, P. C. Allelopathy of leaf extracts of jatropha (Jatropha curcas L.) in the initial development of wheat (Triticumaestivum L.). Idesia, Chile, v. 31, n. 1, p. 45-52, 2013.

SILVA, F. M.; AQUILA, M. E. A. Potencial alelopático de espécies nativas na germinação e crescimento inicial de Lactuca sativa L. (Asteraceae). Acta Botânica Brasílica, São Paulo, v. 20, n. 1, p. 61-69, 2006.

SILVA, A. A.; SILVA J. F. Tópicos em manejo de plantas daninhas. Viçosa: Ed. UFV, 1 ed. 2007, p. 367. 
SILVA, H. L.; TREZZI, M. M.; BUZZELLO, G.; PATEL, F.; MIOTTO JR, E.; DEBASTIANI, F. Potencial supressivo de genótipos e níveis de palha de girassol (Helianthus annuus L.) sobre o desenvolvimento de picão preto (Bidens pilosa). Revista brasileira de Agrociência, Pelotas, v. 17, n. 1, p. 10-20, 2011.

SOUZA FILHO, A. P. S.; LÔBO, L. T.; ARRUDA, M. S. P. Atividade alelopatica em folhas de Tachigali myrmecophyla (Leg.PAP). Planta Daninha, Viçosa, v. 23, n. 4, p. 557-564, 2005.

SOUZA FILHO, A. P. S.; DUTRA, S. Germinação de sementes de calopogônio (Calopogonium mucunoides). Pasturas Tropicales, Cali, v. 20, n. 3, p. 26-30, 2000.

SPEAR, D.; FOXCROFT, L. C.; BEZUIDENHOUT, H.; MCGEOCHET, M. A. Human population density explains alien species richness in protected areas. Biology of Conservation Magazine, Australia, v. 159, p. 137147, 2013.

VILÀ, M.; ESPINAR, J. L.; HEJDA, M.; HULME, P. E.; JAROSIK, V.; MARON, J. L.; PERGL, J.; CHAFFNER, U.; SUN, Y.; PYSEK, P. Ecological impacts of invasive alien plants: a meta-analysis of their effects on species, communities and ecosystems. Ecology Letters, California, v. 14, p. 702-708, 2011.

ZENG, R. S.; MALLIK, A. U; LUO S. Allelopathy in Sustainable Agriculture and Forestry. New York: Springer Verlag, 2010, 426p. 